\title{
LA INFLUENCIA DE BECCARIA EN EL DERECHO PENAL MODERNO*
}

\author{
Manuel Alberto Leyva Estupiñán** \\ Larisbel Lugo Arteaga***
}

\begin{abstract}
Resumen: La obra de CÉSAR BECCARIA De los delitos y las penas constituye un pilar para el Derecho Penal contemporáneo porque sustenta las principales ideas del liberalismo penal que, posteriormente al siglo XVIII, se manifiestan en el pensamiento penal occidental. BECCARIA constituye uno de los abanderados que desde la filosofía y el Derecho penal desmontan el sistema inquisitivo de enjuiciar, propio del Derecho canónico de la época, para un sistema que incorporara mayores garantías para el procesado. En esta obra, se critican la sanción de muerte y los tormentos infligidos a los acusados, y se perfila la
\end{abstract}

* Fecha de recepción: 2 de febrero de 2015. Fecha de modificación: 12 de diciembre de 2015. Fecha de aceptación: 15 de enero de 2016. Para citar el artículo: LeYva Estupiñán, ManuEl AlberTo y Lugo Arteaga, Larisbel (2015). "La influencia de Beccaria en el Derecho Penal moderno", Revista Derecho Penal y Criminología, Vol. 37, n. ${ }^{\circ} 101$, julio-diciembre de 2015. Bogotá: Universidad Externado de Colombia, pp. 133-151. DOI: http://dx.doi.org/10.18601/ 01210483.v36n101.05

** Profesor Auxiliar de Derecho Penal en la Universidad de Holguín, Cuba. Licenciado en Derecho en 2005 por la Universidad de Camagüey, Cuba. Especialista en Derecho Penal por la Universidad de Holguín. Actualmente cursa el doctorado en Ciencias Jurídicas por la Facultad de Derecho de la Universidad de Oriente, Cuba. Profesor en la República Bolivariana de Venezuela durante los años 2008 y 2009. Miembro de la Sociedad Cubana de Ciencias Penales. Se desempeña como Jefe del Departamento de Derecho en la Facultad de Ciencias Sociales y Jurídicas de la Universidad de Holguín. Camagüey, Cuba. Correo-e: mleyvae@fh.uho.edu.cu

*** Profesora Asistente de Derecho Penal Especial en la Universidad de Holguín, Cuba. Licenciada en Derecho en 2005 por la Universidad de Camagüey, Cuba. Se desempeñó como jueza en el Tribunal Provincial Popular de Camagüey en su Sala Quinta de lo Penal. Especialista en Derecho Penal por la Universidad de Holguín. Camagüey, Cuba. Correo-e: 1lugo@fh.uho.edu.cu 
prevención como fin de la pena, así como las bases de varios de los principios de las ciencias penales de la contemporaneidad.

Palabras clave: BeCCARIA; Derecho Penal; Sanción; Principios; Sistema de enjuiciar; Función de la pena; Garantías de los acusados; Historia del Derecho penal.

\title{
THE INFLUENCE OF BECCARIA IN MODERN CRIMINAL LAW
}

\begin{abstract}
On Crimes and Punishments" by Cesar BECCARIA is a fundamental work for modern Criminal Law. The ideas of liberal Criminal Law are presented throughout the book and the basis of philosophy used as a criteria, clearly reappears in Western thought by the middle of the 18th Century. BECCARIA is one of the first authors that actually criticize the inquisitive system and canonical law from a philosophical and Criminal Law point of view. The author criticizes capital punishment, tortures to the accused and concludes that prevention should be the final objective of punishment.

Keywords: BECCARIA; Punishment; Prevention of Torture; History of Criminal Law.
\end{abstract}

\section{INTRODUCCIÓN}

Han transcurrido dos siglos y medio de la publicación de la obra De los delitos y las penas, de CÉSAR BECCARIA, y merece la pena realizar una revisión de cuánto ha influido en el pensamiento jurídico penal del mundo occidental. Constituye una obra revolucionaria desde todo punto de vista. Los planteamientos de BECCARIA en materia de principios y garantías constituyen bases para la existencia de un Derecho Penal garantista y humano en la contemporaneidad. Algo similar ocurre en su crítica a la sanción de muerte, una pena que ha llegado hasta nuestros días y que es objeto de permanente debate.

La obra de BECCARIA marca un viraje en el tratamiento al proceso penal, en los fines de la pena, donde se muestra fervoroso partidario de la prevención, más que la tradicional concepción retribucionista de la época. Sienta bases sólidas desde el punto de vista teórico para el tránsito desde el sistema inquisitivo de enjuiciar hacia un sistema mixto. A la colonia cubana llegan de la mano de la metrópoli española las ideas relacionadas con el proceso penal, de hecho con menor influencia que en regiones como los Estados Unidos o el propio Haití, mucho más cercanos al resplandor de la Revolución Burguesa de 1789. En resumen, puede hablarse de un antes y un después en la historia del pensamiento penal a partir de la publicación de De los delitos y las penas. Constituye la piedra angular desde el punto de vista penal de la rica tradición latina continental. 


\section{ANTECEDENTES FAMILIARES E HISTÓRICOS DE BECCARIA}

Cuando CÉSAR BONESANA, posteriormente conocido como marqués de BECCARIA, con solo 26 años de edad publicaba Dei delitti e delle pene ${ }^{I}$ en 1764, lejos estaba de imaginar que su ensayo influiría en el pensamiento penal continental durante los siglos siguientes. Se dice que era temeroso (publicó su obra bajo el anonimato, y solo cuando la publicidad ganada le granjeó seguridad, asumió su autoría). Cómo no serlo ante un Tribunal del Santo Oficio que podía mandarlo a la muerte.

Dos años antes, su obra inicial Del disordine o dei remedi della monete nello Stato di Milano (Del desorden de la moneda y su remedio en el Estado de Milán) era una mescolanza de lo que hoy llamaríamos Derecho Mercantil, Derecho Económico y Derecho Administrativo. El joven CÉSAR colabora en su juventud en el periódico Il Caffé desde junio de 1764 hasta junio de 1776, donde se desarrollan algunas de las ideas que quedaron plasmadas en su obra cumbre.

En el campo de la economía, tiene obras reconocidas como "Curso de Economía" desde la cátedra que asumió, donde resulta un precursor del proteccionismo económico de las naciones. Estas producciones han quedado en el olvido ante la magnitud de su obra cumbre. Autores como Schumpeter han llegado a compararlo en el campo de la economía con Adan Smith. En el ambiente ilustrado de Milán, contribuyó a la fundación de la Accademia dei Pugni ("Academia de los puños").

Para entender el pensamiento de BECCARIA no basta con la lectura meticulosa de su obra. Resulta necesario adentrarse en las condiciones de la época en que vivió, las dificultades afrontadas en su juventud y las ideas prevalecientes en la Europa fragmentada del Medioevo, que ya había observado la revolución inglesa un siglo antes, a principios de 1642 y a solo dos décadas de que estallara la Revolución Francesa de 1789. Es una Europa donde el capitalismo va abriéndose paso y enterrando de manera lenta pero inexorable al sistema feudal, la ilustración sustituyendo al oscurantismo que durante siglos, y de la mano de la iglesia católica, se impuso como doctrina oficial de los estados.

En el campo del Derecho se abre paso la concepción del Derecho Natural, anterior y superior al Derecho positivo, del cual emanaban todas las demás manifestaciones del Derecho. En el campo del Derecho Procesal, la humanidad comenzaba a salir del sistema inquisitivo y se adentraba en lo que posteriormente se ha conocido como el sistema mixto de enjuiciar. Por la época en que se publica la obra de BECCARIA, los jueces del Tribunal de la Inquisición cerraban sus ojos al aforismo latino de Justinia-

1 Traducida al español como Tratado de los delitos y de las penas, por el español por D. JUAN ANTONIO DE LAS CASAS, edición de 1774, Madrid: Ed. D. Joachin Ibarra, Impresor de Cámara de S.M. 
no contenido en el Digesto del 533 d.C. y que rezaba: "Satius enim esse impunitum relinqui facinus nocentis, quam innocentem damnari" 2 .

Los BONESANA habían constituido una fuerte familia durante los siglos XIII y XIV, en lo que hoy llamamos Italia. Estuvieron involucrados en las luchas fratricidas entre güelfos y gibelinos, papistas y antipapistas. Cuando en 1418, por orden del Duque Felipe María Visconti se ejecuta mediante la horca a Lancelote BECCARIA, la suerte cambia definitivamente, en detrimento de los BECCARIA. A mediados del siglo XVIII, es otro el estatus de su familia.

Las exigencias en materia de disciplina impuestas por su padre en la adolescencia, si bien constituyeron duras experiencias de privaciones y castigos -según sus propias palabras-, posibilitaron que alcanzase una educación exquisita. Estudió con los seguidores de San Ignacio de Loyola, la Orden de los Jesuitas (Societas Iesu) durante ocho años, por mucho la orden religiosa que más contribuyó desde la fe católica a la instrucción y educación de la sociedad ${ }^{3}$. Son los jesuitas los fundadores del mayor número de universidades y colegios de este periodo, incluyendo la Real y Pontificia Universidad de San Gerónimo de la Habana en 1728. Posteriormente, continúa sus estudios en la Universidad de Pavía, de la cual se gradúa como abogado.

Cuando Guillermo CABAnEllas aborda este periodo de la vida de CÉSAR, Magister dixit que el Tratado de los delitos y las penas constituye una reacción juvenil a los tormentos experimentados por el autor. Con solo 22 años, BONESANA sufre prisión, solicitada por su padre, el marqués de BECCARIA, quien se oponía a la relación de su hijo con TERESA DE BLASCO. Es allí, en la dura cárcel del lejano 1760, donde padece en carne propia los rigores y tormentos de la prisión. El sistema penitenciario propio del Derecho Canónico de la época sin dudas siembra en el joven juicios contrarios al mismo. Por lo tanto, su filosofía relacionada con la pena y el delito está marcada por vivencias propias ${ }^{4}$.

Consideramos que la educación recibida marcó su manera de ver el mundo, y a la vez influyó en el desmontaje posterior de esta visión, al encontrarse con la lectura de los autores de la Ilustración, fundamentalmente francesa, entre los que se contaba

2 "Es mejor dejar libre a un culpable que castigar a un inocente".

3 Si bien la Orden de los jesuitas en el pasado fue expulsada de reinos y criticada por prominentes figuras, en el siglo xx asumió diversas corrientes, entre ellas, la progresista Teología de la Liberación en América Latina (nota de los autores).

4 "He oído el ruido de las cadenas que sacuden la superstición y el fanatismo, ahogando los gemidos de la verdad. La contemplación de ese espectáculo espantoso me determinó, a veces, a envolver la luz con nubes. He querido defender a la Humanidad sin hacerme su mártir". Palabras de BECCARIA al abate Morellet, su traductor al francés del Tratado de los delitos y de las penas (Cfr. en CABANELLAS, 1993, pp. 20 y ss.). 
VOLTAIRE, quien posteriormente también alaba su obra y llega a tener un encuentro con BECCARIA cuando este viaja a Francia.

Antes de morir el 28 de noviembre de 1793 a la edad de 55 años, víctima de un ataque de apoplejía, fue nombrado miembro de la Junta per la rifonnu del sistema giudiziario civile e criminale.

\section{EL LIBRO DE LOS DELITOS Y LAS PENAS}

La importancia del libro de BECCARIA es manifiesta, toda vez que en un breve espacio de tiempo se publica en 22 idiomas. En la Francia prerrevolucionaria, marcó un antes y un después. Sería interesante poder determinar hasta qué punto influyó el Tratado de los delitos y las penas en la Declaración de los derechos del hombre y el ciudadano, del 26 de agosto de 1789. En los artículos seis, siete y ocho ${ }^{5}$ pueden vislumbrarse algunos de los principios y garantías de orden procesal enunciados por BECCARIA veinticinco años antes. La influencia no se manifestó solamente en los documentos jurídicos emanados al calor de la Revolución francesa, sino que caló de manera profunda en los hombres que impartían la justicia, y que asumieron una actitud ante el delito y la pena diferente a la sostenida durante siglos. Al respecto, podrían ser interesantes las palabras de uno de ellos: “Todos los jóvenes magistrados de las Cortes, y puedo atestiguarlo porque yo era uno de ellos, juzgan más según los principios de esa obra que según las leyes" (BECCARIA, Op. cit., p. 30).

BecCARia sería un seguidor de las ideas de Montesquieu. Manifestó haber leído "Las cartas persas" así como su obra maestra De l'esprit des lois (El espíritu de las leyes). Es así como las ideas relacionadas con el poder emanan de BECCARIA contrarias al absolutismo imperante, siendo sobrio defensor de la división de poderes defendida por el Señor de la Brède y Barón de MonTESQuiEu. En la actualidad, el Derecho Constitucional del mundo occidental es mayormente partidario -con lógicas adecuaciones- a esta división de poderes. La denominación que asumen el legislativo, ejecutivo y judicial han variado, pero la esencia sigue siendo la misma

5 Artículo VI. La ley es expresión de la voluntad de la comunidad. Todos los ciudadanos tienen derecho a colaborar en su formación, sea personalmente, sea por medio de sus representantes. Debe ser igual para todos, sea para proteger o para castigar. Siendo todos los ciudadanos iguales ante ella, todos son igualmente elegibles para todos los honores, colocaciones y empleos, conforme a sus distintas capacidades, sin ninguna otra distinción que la creada por sus virtudes y conocimientos. VII. Ningún hombre puede ser acusado, arrestado y mantenido en confinamiento, excepto en los casos determinados por la ley, y de acuerdo con las formas por ésta prescritas. Todo aquél que promueva, solicite, ejecute o haga que sean ejecutadas órdenes arbitrarias, debe ser castigado, y todo ciudadano requerido o aprehendido por virtud de la ley debe obedecer inmediatamente, y se hace culpable si ofrece resistencia. VIII. La ley no debe imponer otras penas que aquéllas que son estrictamente y evidentemente necesarias; y nadie puede ser castigado sino en virtud de una ley promulgada con anterioridad a la ofensa y legalmente aplicada. 
presentada por MONTESQUiEu y asumida en su obra por BECCARIA. En el llamado socialismo del siglo xxi, la Constitución de la República Bolivariana de Venezuela, además de estos tres poderes, incluye el Poder Electoral y el Poder Ciudadano, este último siguiendo las ideas del Libertador SiMÓN BoLíVAR.

Sin embargo es -a nuestro modo de ver- JUAN JACOBO RouSSEAU quien mayor influencia ejerce sobre CÉSAR BONESANA. La teoría del contrato social esgrimida por el suizo está presente en la obra de CÉSAR:"La primera consecuencia de estos principios es que sólo las leyes pueden decretar las penas de los delitos; y esta autoridad debe residir únicamente en el legislador, que representa toda la sociedad unida por el contrato social" (BECCARIA, Op. cit., p. 61).

Esta concepción del contrato social, dentro del iusnaturalismo como corriente ideológica y jurídica de finales del siglo XVIII, ha sido retomada una y otra vez para encontrarle justificación, desde otras posiciones a las relaciones entre Estado-sociedadindividuo. En el ámbito penal, BECCARIA puede ser considerado uno de los precursores de la teoría de la dañosidad social. Si el delito representaba -según BonESANA- un daño a la sociedad, la llamada Escuela de la Defensa Social sin lugar a dudas tiene en él a uno de sus padres fundadores. Si bien puede resultar hoy incorrecta una concepción que afirmaba el origen del Estado y las leyes en obligaciones emanadas de un contrato primigenio, constituía una valiente crítica al sistema de las monarquías absolutas, y de forma más velada al propio Derecho canónico de la iglesia católica. Para una teoría marxista del delito -que podemos considerar en permanente construcción- resulta dogmáticamente más garantista y eficaz hablar de la dañosidad social como uno de los rasgos del delito que los criterios de la peligrosidad social heredados del socialismo del este europeo con claras influencias del positivismo italiano de inicios del siglo xx. Con la dañosidad social podríamos hablar ciertamente de lesividad (Nullum crimen sine injuria) como principio del Derecho penal, donde solo se justifica la aplicación de la pena cuando se han lesionado o puesto en peligro bienes jurídicos fundamentales.

\section{EL IUS PUNIENDI Y EL FIN DE LAS PENAS}

En la actualidad, la concepción predominante sobre el llamado ius puniendi del Estado es considerarlo como un derecho a castigar, reconocido al Estado por la propia constitución. El derecho a castigar, según tales criterios, tiene carácter constitucional. "[...] el ius puniendi ha de ejercerse en la sola medida exigida por la protección de la sociedad, es el llamado carácter fragmentario del Derecho penal. Significa que el Derecho penal no sanciona todas las conductas lesivas de bienes jurídicos, sino sólo las modalidades de ataque más peligrosas para ellos" (MIR PUIG, 1976, p. 126). Tales ideas podrían resultarnos novedosas, y no lo son tanto cuando el propio BECCARIA definía que el soberano tenía el derecho a castigar ante la comisión de un delito. Y ese derecho, según el autor italiano, descansaba en el contrato social establecido 
entre el soberano y la sociedad. Al respecto, manifestó: "Veis aquí la base sobre que el Soberano tiene fundado su derecho para castigar los delitos: sobre la necesidad de defender el depósito de la salud pública de las particulares usurpaciones; y tanto más justas son las penas, cuanto es más sagrada e inviolable la seguridad, y mayor la libertad que el Soberano conserva a sus súbditos".

En nuestro criterio, más que derecho subjetivo del Estado ${ }^{6}$ o potestad del Estado para castigar $^{7}$ constituye un límite en sí mismo, límite formal, pues estaríamos hablando del Estado autolimitándose en sus funciones. En nuestro criterio el ius puniendi constituye una función del Estado ${ }^{8}$, un deber ${ }^{9}$, una obligación (Obligatio ad faciendum) generada por las propias funciones del Estado.

Al valorar el marqués BECCARIA los fines de la pena, se muestra crítico contra los tormentos infligidos por el sistema penal de la época. No es cosa de cuentos, basta leer los tormentos ocasionados ${ }^{10}$ a un acusado, que aparecen en la publicación perió-

6 Soler (1992, p. 13); Mir Puig (Ob. cit., p. 98); Medina Cuencia (2001).

7 NúÑEZ (1999, p. 15); Quintero Olivares (1976, p. 37).

8 Autores como CARBONELL MATEU (1996, p. 102) plantean que "ha de considerarse indiscutible que no se trata del ejercicio de ningún derecho subjetivo, sino de las funciones que corresponden al Estado en virtud del pacto social traducido en la Constitución. El poder de crear normas penales no tiene diferentes características que el de legislar en materia de cultura, obras públicas o educación, si bien, a diferencia de esas materias, y como ya sabemos, el Derecho penal supone recortes a la libertad general con el fin de tutelar las libertades de los ciudadanos".

9 La concepción tradicional del ius puniendi como derecho a castigar del Estado resulta a nuestro modo de ver, incorrecta. Desde una concepción liberal ciertamente podría defenderse la categoría derecho, lo cual refuerza criterios como la existencia de una relación cuasicontractual entre Estado e individuo. ¿Por qué nace en el individuo que comete un delito la obligación de sufrir una pena? Desde una posición marxista, que niega llevar al plano contractual las relaciones Estado-sociedad civil, más que derecho debe considerarse potestad y deber. Potestad porque solo el Estado está legitimado a través de sus órganos jurisdiccionales para dictar las leyes y perseguir los delitos. Constituye a la vez un deber que se sustenta en las funciones del Estado. El Estado tiene el deber de delimitar las conductas constitutivas de delito y la obligación -no derecho-a perseguirlas y sancionarlas. La razón de ser del Estado es precisamente garantizar la coexistencia, la estabilidad de la sociedad, tiene encomendado ese rol. Para poder cumplirlo de forma satisfactoria deberá prohibir y penal determinadas conductas, a fin de poder proteger de manera efectiva los bienes jurídicos políticamente importantes para la clase dominante (Cfr. FontÁn BALESTRA, 1998, pp. 14 y 15; ZAFFARONI, 1998, pp. 33 y ss.).

10 Amiens fue condenado, el 2 de marzo de 1757, a "pública retractación ante la puerta principal de la Iglesia de París", adonde debía ser "llevado y conducido en una carreta, desnudo, en camisa, con un hacha de cera encendida de dos libras de peso en la mano"; después, "en dicha carreta, a la plaza de Grève, y sobre un cadalso que allí habrá sido levantado [deberán serle] atenaceadas las tetillas, brazos, muslos y pantorrillas, y su mano derecha, asido en ésta el cuchillo con que cometió dicho parricidio, quemada con fuego de azufre, y sobre las partes atenaceadas se le verterá plomo derretido, aceite hirviendo, pez resina ardiente, cera y azufre fundidos juntamente, y a continuación, su cuerpo estirado y desmembrado por cuatro caballos y sus miembros y tronco consumidos en el fuego, reducidos a cenizas y sus cenizas arrojadas al viento." Finalmente, se le descuartizó, refiere la Gazette d'Amsterdam. Esta última operación fue muy larga, porque los caballos que se utilizaban no estaban acostumbrados a tirar; de suerte que en lugar de cuatro, hubo que poner seis, y no bastando aún esto, 
dica de Ámsterdam siete años antes de la publicación de su libro, y que seguramente presenció mientras estuvo en prisión ${ }^{11}$.

La obra de BECCARIA ha sido considerada por ANTÓN ONECA (1964, p. 415) como el "evangelio de los reformadores". La concepción retribucionista de considerar la pena como un mal que habría de ocasionársele a quien había producido otro mal es superada por CÉSAR. Puede considerársele el padre de la teoría de la prevención como fin de la pena. Al respecto, señalaba: "Es mejor evitar los delitos que castigarlos. He aquí el fin principal de toda buena legislación, que es el arte de conducir los hombres al punto mayor de felicidad o al menor de infelicidad posible, para hablar según todos los cálculos de bienes y males de la vida (...) El temor de las leyes es saludable" (BECCARIA, Op. cit., p. 158).

Desde BECCARIA nos ha llegado -y aún existe- el criterio según el cual la sanción no puede pretender la restauración del orden jurídico. El delito es en primer lugar (aquí se manifiesta su organicidad con la teoría del contrato social) un daño a la sociedad, afecta a los individuos que han acordado ciertas reglas para una convivencia de personas y derechos. El delincuente representa un peligro para la sociedad. Visto así, la teoría del estado peligroso también pareciera estar asentada en la obra del autor italiano: "El freno más eficaz contra el delito no es el terrible y fugitivo espectáculo de la muerte de un criminal, sino el prolongado y penoso ejemplo de un hombre privado de libertad, el cual recompensa con sus fatigas a la sociedad injuriada" (ídem, p. 33). Recordemos que en la actualidad JAKOBS contrapone la vigencia de la norma como función del Derecho Penal a la concepción predominante ${ }^{12}$ enfocada en la protección de bienes jurídicos, y la prevención como fin de la pena. El profesor de BonN nos recuerda al maestro KELSEN al defender en una de sus obras cumbre, La teoría pura del Derecho (1935), el concepto del Derecho como entidad autónoma de concepciones ideológicas y morales.

SANCINETi (2006, p. 53) también afirma que la idea de un Derecho penal como protector de bienes jurídicos resulta expansiva del poder punitivo, pues si se pretende erigir a la amenaza de pena en un escudo protector de bienes, qué más conveniente que "incrementar el grosor de ese escudo" (incrementar las penas) para lograr una más eficaz protección. Y añade que tal protección no puede ser realizada fácticamente (KIERSZENBAUM, 1999).

fue forzoso para desmembrar los muslos del desdichado, cortarle los nervios y romperle a hachazos las coyunturas (...) Tomado de Foucault (s.f., p.1).

11 Las referencias a su estadía en prisión, procedentes de la obra de Cabanellas, han sido refutadas en fechas más cercanas por autores como CÉSAR CANTÚ (1862, p. 92), se ha establecido que decretado el arresto, por petición suya, tal arresto lo cumplió en su casa. Sobre lo anterior, puede verse también a JAVIER LLOVET (2011, pp. 21 y 22).

12 Cfr. Roxin (1997, p. 52), Bacigalupo (1996, p. 6), JoAchimrudolphi (1991, p. 82), Mir Puig (2003, p. 147), ZAFFARONI (1998, p. 24) Quirós PíreZ (1999. p. 158). 
"Si el Derecho penal realmente pudiera cumplir la misión de "proteger bienes jurídicos" en sentido físico, como si fuera un vidrio blindado que se levantase delante de los bienes, ciertamente sería correcto aumentar el grosor del vidrio tanto como fuera posible, pues cuanto más denso fuese el blindaje, mayor sería la protección. Pero esa noción es errada. La ley penal no es un "escudo protector"; ni pretende, ni puede lograr que el delito desaparezca. Ésa no es una misión que deba serle adscripta como cosa propia ni siquiera en forma ideal. No es que por el hecho de que la ley penal sea incapaz de cumplir esa misión deba desaparecer: sólo significa que no protege, al menos no si por protección se entiende un escudo real contra el agresor eventual". BeCCARIa (FoucAult, Op. cit., p. 61) ha mostrado su rechazo a la pena de muerte y expuesto como sustituta de esta la esclavitud perpetua. ¿Pena físicamente más cruel que la muerte? De ningún modo, decía; porque el dolor de la esclavitud está dividido para el condenado en tantas parcelas como instantes le quedan que vivir; pena indefinidamente divisible, pena eleática, mucho menos severa que el castigo capital que, de un salto, se empareja con el suplicio. En cambio, para quienes ven o se representan a esos esclavos, los sufrimientos que soportan están reunidos en una sola idea; todos los instantes de la esclavitud se contraen en una representación que se vuelve entonces más espantosa que la idea de la muerte.

Es la pena económicamente ideal: es mínima para aquel que la sufre (y que, reducido a la esclavitud, no puede reincidir) y es máxima para aquel que se la representa. "Entre las penas y en la manera de aplicarlas en proporción a los delitos, hay que elegir los medios que hagan en el ánimo del pueblo la impresión más eficaz y la más duradera, y al mismo tiempo la menos cruel sobre el cuerpo del culpable".

\section{BECCARIA COMO PRECURSOR DE ALGUNOS PRINCIPIOS DE LAS CIENCIAS PENALES}

De una lectura sosegada de la obra de BECCARIA pueden sacarse a la luz los antecedentes de varios principios de las ciencias penales. Muchas de las categorías e instituciones que hoy se manifiestan en la dogmática penal contemporánea parten de dicho pensamiento. Como se recordaba en páginas anteriores, para analizar su obra hay que adentrarse en el complejo panorama que experimentaba el proceso penal de la Europa del siglo XVIII. El abandono durante siglos de las bases del sistema acusatorio y el desarrollo de un proceso inquisitorial hacen de este periodo una combinación de perversidades humanas en nombre de la fe. El abandono de la contradicción y la igualdad de las partes como piedra angular del debido proceso, de la duda en favor del reo, fueron sustituidos por el in dubio pro fidei (en caso de duda, se favorece la causa de la Fe).

Por tanto, no son todos los principios los que se analizan en las páginas siguientes. Solo una pincelada de varios de los que se manifiestan a criterio de los autores. 
El debido proceso en materia penal "es todo ese conjunto de garantías que protegen al ciudadano sometido al proceso penal, que le aseguran a lo largo del mismo una recta, pronta y cumplida administración de justicia; que le otorgan la libertad y la seguridad jurídica, la racionalidad y la fundamentación de las resoluciones judiciales conforme a derecho" (MADRID-MALO GARIZÁBAL, 1997, p. 51).

El debido proceso, como megaprincipio, principio base, ideal de justicia o cualquiera de las múltiples maneras de reconocérsele, tiene lejanos antecedentes. En el Tratado de los Delitos y las Penas pueden identificarse varios de sus postulados. Desde el punto de vista histórico se suelen identificar sus antecedentes en la ya aludida Carta Magna inglesa sancionada por el rey JUAN I ${ }^{13}$ en Londres el 15 de junio de 1215 y que recogía bases para un debido proceso como las siguientes:

"Ningún hombre libre será detenido ni preso, ni desposeído de sus derechos ni posesiones, ni declarado fuera de ley, ni exiliado, ni perjudicada su posición de cualquier forma, ni nos procederemos con fuerza contra él, ni mandaremos a otros hacerlo, a no ser por un juicio legal de sus iguales o por ley del país (...) No venderemos, ni rehusaremos, ni dilataremos a nadie la administración de justicia" (VALLE MoLINA, s.f.). No obstante, pueden encontrarse antecedentes más remotos de este principio en la Europa medieval, en las Cortes de León que se celebraron a comienzos del reinado de ALFONSO IX, en el año 1188. Entre las garantías contenidas se consideraba la inviolabilidad del domicilio, del correo, la necesidad del rey de convocar Cortes para hacer la guerra o declarar la paz, y se garantizaban numerosos derechos individuales y colectivos, entre otras.

La frase de RoussEAu “(...) El hombre nace libre, pero en todos lados está encadenado", unido a sus propias vivencias en prisión, le define en su cosmovisión el poder absoluto que gozaban los que ostentaban el poder. Es un convencido partidario de las garantías en materia penal.

En el orden probatorio expresaba que "Siempre es necesario más de un testigo; porque en tanto que uno afirma y otro niega no hay nada cierto, y prevalece el derecho que cada cual tiene de ser creído inocente" (BECCARIA, Op. cit., p. 81). De igual manera podría considerarse un crítico de la exigencia de la confesión como prueba tasada y de mayor valor que el resto. Los tormentos a los cuales se sometían los acusados en búsqueda de la confesión le resultaban repugnantes. La libre apreciación de la prueba, sin considerar una de mayor jerarquía que otra, constituye un planteamiento valiente y a la vez avanzado para su tiempo: "Cuando mayores pruebas se traen,

13 Desde el punto de vista literario resulta interesante que Juan sucede en el trono a Ricardo I de Inglaterra, más conocido como Ricardo Corazón de León, a quien el personaje de Robin Hood defiende y reconoce como su verdadero rey. 
tanto más crece la probabilidad del hecho, porque la falacia de una prueba no influye sobre la otra" (ídem, p. 83).

Al respecto, expresó: "Las formalidades y las ceremonias son necesarias en la administración de la justicia, ya que nada dejan al arbitrio del que la administra, ya porque dan idea al pueblo de un juicio, no tumultuario e interesado, sino estable y regular, ya porque los hombres, esclavos o imitadores de la costumbre, hacen impresiones más eficaces las sensaciones que los raciocinios" (ídem, p. 50).

A continuación, relacionamos algunos de los principios reconocidos por la doctrina en materia penal y que pueden ser considerados componentes del Debido Proceso Penal o al menos están estrechamente relacionados con el mismo.

Con relación al principio de legalidad de los delitos y las penas, puede considerarse a BECCARIA uno sus padres. Si bien es cierto que la mayoría de los autores reconocen su origen en la Carta Magna de Juan sin Tierra de 1215, la amplitud del mismo, desde el ámbito inglés, se reducía a la nobleza. El movimiento revolucionario de la burguesía, fundamentalmente la francesa del siglo XVIII, es la que le confiere un carácter más popular, más general a este principio, llegando a configurarlo como una garantía de primer orden para los acusados ante los excesos del poder absoluto. "Son las leyes únicamente las que pueden decretar penas respecto a los delitos y el juez nunca debe ser habilitado para usurpar la potestad del legislador. Su obra debe ser un silogismo perfecto cuya proposición mayor es la ley, la menor es el hecho que está resolviendo, y la conclusión debe ser la libertad del acusado o la pena" (ídem, p. 61). No consideramos que la culpabilidad como principio esté recogido en la obra de BECCARIA, al menos no de manera implícita como si lo están otros principios de las ciencias penales. Se considera en la actualidad que su despliegue teórico está sentado fundamentalmente en la doctrina alemana. Aunque el principio de culpabilidad es en su evolución posterior al de legalidad, el dogma nullum crimen sine culpa constituye uno de los límites reconocidos por la doctrina contemporánea al ius puniendi del estado. En fecha reciente es que se ha comenzado a considerar en las constituciones y códigos penales su incorporación. No obstante lo anterior, hablar de reprochabilidad, de responsabilidad personal, en el sentido de atribuibilidad significa la consideración en todo su alcance de la presunción de inocencia en favor del acusado.

Tampoco resulta sencillo poder encontrar rasgos de culpabilidad en la obra de BECCARIA, en una época donde el libre albedrío constituía desde la religión una filosofía que justificaba la actuación de los hombres contrarios a Dios. Ya no estaban hechos a su imagen y semejanza en el sentido literal, se apartaban de Dios cuando pecaban. Dios les había dado la libertad de elegir entre el bien y el mal. Por tanto, el delito no constituía la voluntad de Dios, sino todo lo contrario, significaba apartarse de Dios.

Los inicios del principio de ultima ratio habrán de buscarse en el pensamiento liberal del siglo XVIII y siguientes. En BECCARIA, encontramos la primera expresión de 
lo que hoy llamamos principio de mínima intervención del Derecho Penal" (AsúA BATARRITA, 1990, p. 9). El humanismo y la proporcionalidad entre la pena y el delito cometido son referentes permanentes en la obra del italiano: "Otro principio sirve admirablemente para estrechar más y más la importante conexión entre el delito y la pena; éste es que sea ella conforme cuanto se pueda a la naturaleza del mismo delito" (BECCARIA, Op. cit., p. 102).

La construcción de un Derecho Penal mínimo va indisolublemente ligado a la Teoría del Garantismo Penal, con FerRajoli como uno de sus máximos exponentes, pero que también ha calado en la América nuestra de la contemporaneidad en autores tan reconocidos y a la vez auténticos como EUGENIO RAÚl ZAFFARONI.

Hablar de Derecho Penal Mínimo es llevar a la esfera de aplicación del Derecho Penal el mínimo de conductas transgresoras. En la evolución del ius puniendi, podemos apreciar que no ha sido lineal, pacífica y que, por demás, no apunta a límites concretos. Hay quienes afirman que el Derecho Penal camina hacia su propia tumba y será reemplazado por un nuevo Derecho correccional construido sobre bases positivistas (DORADo MonTERO, 1995, p. 16 y ss.).

Algunos de los principios del Derecho Penal responden a concepciones de ultima ratio. Entre estos, encontramos el carácter fragmentario y el carácter subsidiario del mismo. Según el principio de subsidiariedad, el Derecho Penal ha de ser la ultima ratio, el último recurso a utilizar a falta de otros menos lesivos. El llamado carácter fragmentario del Derecho Penal constituye una exigencia relacionada con la anterior. Ambos postulados integran el llamado principio de intervención mínima. El Derecho Penal, siguiendo esta línea, solo debe proteger bienes jurídicos; sin embargo, no significa que todo bien jurídico haya de ser protegido penalmente, ni tampoco que todo ataque a los bienes jurídicos penalmente tutelados deba determinar la intervención del Derecho Penal.

Cuando se afirma que el Derecho Penal tiene un carácter fragmentario, se quiere indicar que este solo debe intervenir frente a aquellos comportamientos que atenten contra las reglas mínimas de la convivencia social (esto es, a los bienes o valores jurídicos fundamentales de la persona y de la sociedad), siempre y cuando, además, dichos comportamientos se lleven a cabo de una forma especialmente grave. Cuando se dice que el Derecho Penal es la ultima ratio del ordenamiento jurídico, se quiere indicar que la intervención penal (prevención general del delito a través de la pena) solo es lícita en aquellos supuestos en los que el Estado, previamente, ha agotado todas las posibilidades no penales (culturales, educacionales, asistenciales, de política general) y, pese a todo, de ahí su naturaleza subsidiaria, persisten los conflictos agudos de desviación.

La lesividad u ofensividad como principio ya abordado en páginas anteriores puede identificarse en el Tratado de los delitos y las penas. Su autor exponía: "Hemos visto 
que el daño hecho a la sociedad es Ia verdadera medida de los delitos" (BECCARIA, Op. cit.,p.73). Para ZAFFARONI, el principio de lesividad implica que ningún derecho puede legitimar una intervención punitiva cuando no media por lo menos un conflicto jurídico, entendido como la afectación de un bien jurídico total o parcialmente ajeno, individual o colectivo (ZAFFARONI, 2005, p. 128).

La exigencia de que se lesione o ponga en peligro un bien jurídico penalmente tutelado, constituye una garantía procedimental para el individuo frente al poder sancionador del Estado, estando estrechamente ligado al clásico principio de legalidad. "Algunos delitos destruyen inmediatamente la sociedad o quien la representa; otros ofenden la particular seguridad de alguno o algunos ciudadanos en la vida, en los bienes o en el honor (...) Cualquier delito aunque privado ofende la sociedad" (BECCARIA, Op. cit. p. 74).

Concretar la ofensividad requiere en primer lugar que la conducta encuentre correspondencia en el tipo penal, y supone una valoración especial en los delitos de peligro abstracto o presunto. ¿En qué medida la conducta ha puesto en peligro el bien jurídico tutelado? La existencia del peligro se constituye en la posibilidad del resultado de daño en su futuro y probable desarrollo. No constituye una posibilidad segura, ya que a pesar de la situación de peligro, el resultado dañoso podrá o no producirse. Constituyen delitos de mera actividad.

Otra cuestión se planeta cuando la conducta es casi irrelevante desde el punto de vista penal, lo que podríamos llamar insignificante o exigua. Los llamados delitos "bagatelarios" (reati bagattellari) representan una negación de la lesividad de la conducta, en este caso o no se está protegiendo un bien jurídico o este no es relevante a los efectos penales. Los delitos bagatelarios, por otra parte, suponen la negación del carácter de ultima ratio del Derecho Penal, específicamente su carácter subsidiario. También depende de la dañosidad social de la conducta lesiva, con la que no se corresponde necesariamente la desvaloración del comportamiento lesivo para los bienes" (JAKOBS, 1997, p. 45).

El principio de inmediatez o de celeridad procesal es el derecho a un proceso penal sin dilaciones injustificadas y con prontitud; es otro elemento integrador del Debido Proceso Penal. En tanto este principio de celeridad procesal (VALlE, Op. cit., p.16) es una exigencia para los funcionarios encargados de su ejecución, constituye a la vez un justo reclamo de aquellos que sometidos al proceso penal, cual "espada de Damocles", desean conocer lo antes posible el fallo definitivo de la corte. De ahí que, sin premuras que alteren las garantías del procesamiento y sus necesarios pasos, sea preciso que estos se cumplan para su ejecución con rapidez según los términos reconocidos en las leyes instrumentales. 
En la obra de BECCARIA, pueden leerse las siguientes ideas:

Tanto más justa y útil será la pena cuanto más pronta fuere y más vecina al delito cometido (...) El menos tiempo debe medirse por la necesaria duración del proceso y por la antigüedad de las causas que concede por orden el derecho de ser juzgado (BECCARIA, Op. cit., p. 99).

La publicidad de las actuaciones representa una garantía para el acusado, y a la vez constituye una manifestación de control y acceso popular a la justicia. La publicidad contribuye en segundo orden a la prevención de nuevos delitos. Se puede definir la publicidad como "la inmediata percepción de las actuaciones verificadas por y ante el Tribunal por personas que no forman parte del mismo"14-15. CÉSAR en su magistral obra definía la necesidad de que "Sean públicos los juicios, y públicas las pruebas del relato, para que la opinión, que acaso es el solo cimiento de la sociedad, imponga un freno a la fuerza y a las pasiones, (...) Evidentes, pero consagrados desórdenes son las acusaciones secretas".

De igual manera, antecedentes de la presunción de inocencia aparecen las páginas del Tratado de los delitos y las penas, donde puede leerse que "Un hombre no puede ser llamado reo antes de la sentencia del juez, ni la sociedad puede quitarle la pública protección sino cuando esté decidido que ha violado los pactos bajo que le fue concedida" (BECCARIA, Op. cit., p. 88).

\section{LAS CRÍTICAS A LA SANCIÓN DE MUERTE}

Cuando en el siglo XII, el académico sefardí MAIMÓNIDES escribió que "Es mejor y más satisfactorio liberar a un millar de culpables que sentenciar a muerte a un solo inocente" "16 disparaba los primeros dardos contra la sanción de muerte, en un movimiento que hoy se denomina abolicionismo.

El abolicionismo de la pena de muerte presenta en la actualidad altibajos. Aunque se han sumado un mayor número de naciones a la abolición total de esta sanción de las legislaciones penales, y en algunos casos solo ha quedado reconocida para una cifra pequeña de delitos, también se han verificado retrocesos en el tema. Varios estados han abandonado los pactos y protocolos refrendados en contra de la sanción de muerte.

Según el informe anual de ejecuciones judiciales de Amnistía Internacional, en el año 2003 fueron ejecutadas al menos 1.146 personas en 28 países. El 84\% de las muertes

14 Pedraz Penalva (1989, p. 116).

15 Beccaria (Op. cit., p. 84 y ss.).

16 Wikipedia, La pena de muerte. 
documentadas ocurrieron en cuatro países: la República Popular China llevó a cabo 726 ejecuciones; Irán, 108; Estados Unidos, 65, y Vietnam, 64. La última nación en abolir la pena de muerte para todos los crímenes fue Uzbekistán, a principios de 2008. Singapur es el país con más ejecuciones per cápita del mundo, con 70 ahorcamientos para una población de cerca de 4 millones.

Pueden encontrarse varias páginas de la obra de BECCARIA donde se cuestiona la aplicación de esta sanción. Se encuentran referencias a la muerte cuando aborda el tema de los duelos, del adulterio, en lo referido a los testigos, los jueces a los que nombra de manera indistinta como "comisiones", el secreto y el suicidio, entre otros acápites de su libro. Es un convencido de que el trabajo forzado es mucho más útil al estado que la ejecución del delincuente.

En la enciclopedia Wikipedia, se refleja que a partir de la lectura de la obra de BoNESANA, Leopoldo de Habsburgo, famoso monarca ilustrado y futuro emperador de Austria, abolió la pena de muerte en el entonces independiente Gran Ducado de Toscana el 30 de noviembre de 1786, tras haber detenido de facto las ejecuciones (la última se realizó en 1769).

LEOPOLDO promulgó en esa fecha la reforma del código penal que abolía la pena de muerte, y ordenó la destrucción de todos los instrumentos empleados en su aplicación, en lo que sería la primera prohibición formal de la época moderna. En el año 2000, las autoridades regionales de Toscana establecieron el 30 de noviembre como festividad anual, con el fin de conmemorar el evento. Esa misma fecha se usa a nivel mundial en unas 300 ciudades con el mismo objetivo, formando un movimiento reivindicativo que recibe el nombre de Día de las Ciudades por la Vida.

Varias de las críticas que hoy se le realizan a esta sanción penal encuentran sostén en la obra estudiada. Las principales razones en contra de la aplicación y ejecución de la sanción de muerte aparecen ya en la obra de BECCARIA. Este afirma sin reparos que dicha sanción no tiene el fin intimidatorio que le achacan sus defensores, también ofrece sus criterios en relación a la imposibilidad de reparar la injusticia resultante de aplicarla producto de un error judicial. En la edición en francés realizada por el abate MorelLET ${ }^{17}$, aparece la siguiente nota: “(...) después de las pruebas que les parecerá excluir; como se dice, la posibilidad de la inocencia, no serán siempre infalibles. Podrán si, confundir alguna vez al inocente con el culpable, y condenarle como tal. ¿Y si después, su inocencia sale probada, qué dolor no tendrán por haber cometido una injusticia irreparable? ¿Podrán nunca consolarse de un error tan funesto?" (BECCARIA, Op. cit., p. 126).

17 Esta afirmación no está recogida en De los delitos y las penas, sino en Consulte Criminali, concepto VI, Voto sulla pena de norte. 
La ausencia del fin intimidatorio que se pretende achacar a la sanción de muerte, y que según la mayoría de las investigaciones no existe, aparece de manera muy literal cuando critica el hecho de llevar a la horca a alguien que había robado un caballo en la Inglaterra de la época:

(...) el reo le respondió que parecía muy duro el que se ahorcase a un hombre por haber robado solamente un caballo ${ }^{18}$ : "Tampoco", le dijo el juez, "es por haber robado solamente un caballo que se te ahorca; pero sí, a fin de que los caballos no sean robados". Acto seguido, BONESANA, en un tono que podemos considerar como irónico, continúa: "Los que conocen la Europa en general dicen que se cometen y castigan anualmente más robos en Inglaterra que en todas las otras naciones europeas tomadas colectivamente" (BECCARIA, Op. cit., p. 106).

Este fin intimidatorio no existe, continúa. “(...) es sólo una guerra de la Nación contra un ciudadano, porque juzga útil o necesaria la destrucción de su ser. Pero si demostrase que la pena de muerte no es útil ni es necesaria, habré vencido la causa en favor de la humanidad". Manifiesta que desde el punto de vista histórico no existen en la humanidad referencias a que hayan disminuido los delitos donde aparece prevista. Se refleja en que "la experiencia de todos los siglos, en que el último suplicio no ha contenido los hombres determinados a ofender la sociedad".

BECCARIA se cuestiona la aplicación de la pena capital. “¿Qué derecho pueden atribuirse éstos para despedazar a sus semejantes? Por cierto no el que resulta de la soberanía y de las leyes" (ídem, p. 118 y ss). Desde la ilustración que se abre paso en Europa en una época caracterizada por la victoria del iluminismo frente al oscurantismo y el predominio de la razón, para CÉSAR la sanción de muerte solo ofrece a los hombres un ejemplo de atrocidad. En la traducción francesa aparece a manera de nota que "revestir al hombre del empleo de verdugo, es degradar la humanidad".

Hoy resulta necesario volver a la lectura de esta obra. Valdría la pena valorar que en el año 2006 se ejecutó la sanción de muerte en 25 países, siendo China (1010), Irán (177), Pakistán (82), Irak (65), Sudán (65) y Estados Unidos (53) los que mayor cantidad de personas ejecutaron.

\section{CONCLUSIONES}

El periodo histórico cuando vivió y desarrolló su obra científica CÉSAR BONESANA, marqués de BECCARIA, representa una época de cambios y transformaciones en la

18 Esta frase atribuida por CABANELlas a BECCARIA pertenece en realidad a BENJAMIN FRANKLIN, uno de los padres fundadores de los Estados Unidos de América. 
Europa Medieval. Constituye un momento convulso en el que se enfrentan modelos económicos y corrientes filosóficas diferentes. Este entorno socio-económico marcará pautas en el desarrollo del pensamiento jurídico, permeado por las ideas de la Ilustración que en el ámbito penal suponen el tránsito lento pero inexorable del sistema inquisitivo, con toda su carga de oscurantismo, tormentos y excesos del poder autoritario monárquico hacia un sistema mixto de enjuiciar.

Antes de BECCARIA, venía produciéndose en el campo de la filosofía y el derecho una evolución hacia el llamado Derecho Natural. Empiezan a definirse de manera nítida las bases de varios de los principios y garantías político-procesales que hoy conforman el Derecho Penal Contemporáneo. Lo anterior, unido al entorno familiar de BECCARIA conforma una base filosófica y jurídica que se sintetiza en el libro De los delitos y las penas, una obra de amplia difusión y calado en las generaciones de juristas y filósofos penales de la época y del presente.

El libro de De los delitos y las penas constituye una piedra angular del pensamiento penal contemporáneo. Cuestiones tales como la facultad de sancionar, la legitimidad y fines de las penas, los excesos del poder absoluto de los monarcas y la imperiosa necesidad de actualizar las leyes vigentes de la época son plasmadas en sus páginas de manera magistral.

En la obra de BECCARIA pueden encontrarse claras referencias a las aspiraciones revolucionarias de la burguesía en ascenso, y que constituyen hoy la base del pensamiento penal occidental. Varios de los principios de las Ciencias Penales de la actualidad pueden identificarse en las líneas de la obra de CÉSAR BONESANA. En la misma se realiza una crítica razonada en contra de los suplicios, tormentos, la secretividad, la falta de garantías y la aplicación de la sanción de muerte, entre otros elementos del sistema inquisitivo prevaleciente en el siglo XVIII.

\section{BIBLIOGRAFÍA}

Antón OneCA, J. (1964). "Los fines de la pena según los penalistas de la Ilustración”, en Revista de estudios penitenciarios, n. ${ }^{\circ} 66,1964$, p. 415 . Tomado de Arranz Castillero (2005). El principio de publicidad en los procesos penales. La Habana: Facultad de Derecho, Universidad de la Habana.

Asúa Batarrita, Adela (1990). "Reivindicación o superación del programa BeCCARIA", en Asúa Batarrita, Adela (ed.). El pensamiento penal de Beccaria: su actualidad. Bilbao: Ed. Universidad de Deusto,

Bacigalupo, Enrique (1996). Manual de Derecho Penal, 3. reimp. Bogotá: Editorial Temis. 
BeCCARIA, CÉsAr (1993). De los delitos y las penas. Buenos Aires: Editorial Heliasta S.R.L.

Carbonell Mateu, Juan Carlos (1996). Derecho Penal: concepto y principios constitucionales. 2. ${ }^{a}$ ed., adaptada al Código Penal de 1995. Tirant lo Blanch.

Dorado Montero, Pedro (1995). “Del Derecho Penal represivo al preventivo”, en Derecho Protector de los Criminales. Madrid.

FouCAUlt, Michel. Vigilar y castigar. p.1. En www.pensamientopenal ar [consultado el 12 de abril de 2013. 11.34 a.m].

Fontán Balestra, Carlos (1998). Derecho Penal. Introducción y Parte general. Buenos Aires: Abeledo-Perrot.

Medina Cuenca, Arnel (2001). Los principios limitativos del ius puniendi. Su incidencia en la determinación de la pena y su consagración en las constituciones nacionales y en los instrumentos jurídicos adoptados por la comunidad internacional. Trabajo de investigación defendido en opción del título de Máster en Derecho público, en el Departamento de Derecho Penal de la Facultad de Derecho de la Universidad de Valencia, España, mayo de 2001.

Mir Puig, Santiago (1976). Introducción a las bases del Derecho penal. Barcelona: Ed. Bosch.

NúÑEz, Ricardo C. (1999). Manual del Derecho Penal - Parte general. 4. ${ }^{\mathrm{a}}$ ed. actualizada por Roberto E. SPINKA y FÉLIX GonzÁLEZ. Argentina: Editorial Córdoba.

Jakobs, GüNTher (1997). Derecho Penal (Parte general). Fundamentos y Teoría de la Imputación. 2. ${ }^{\mathrm{a}}$ ed. corregida. Traducción de Joaquín Cuello Contreras y José Luis Serrano González de Murillo. Madrid: Editorial Marcial Pons.

Pedraz Penalva, E. (1989). Notas sobre publicidad y proceso, en Poder Judicial, n. ${ }^{\circ}$ XI especial, C.G.P.J. El Poder Judicial en el Consejo de los Poderes del Estado y de la Sociedad.

Quintero Olivares, G. (1976). "Potestad punitiva”, en Represión penal y Estado de Derecho. Barcelona.

Quirós Pírez, Renén (1999). Manual de Derecho Penal. Tomo I. La Habana: Editorial Félix Varela.

Roxin, Claus (1997). Derecho Penal. Parte general. Tomo I. Fundamentos. La estructura de la Teoría del Delito. Editorial Civitas. 
Soler, Sebastián (1992). Derecho Penal argentino. Buenos Aires: Tipográfica Editora Argentina.

Valle Molina, Pedro Gilberto (s.f.). El Debido Proceso Penal en Cuba y su posible perfeccionamiento. Facultad de Derecho, Universidad de Camagüey.

WIKIPEDIA.

Zaffaroni, Eugenio Raúl (1998). Tratado de Derecho Penal. Parte general. Tomo I. Buenos Aires: EDIAR. 